\title{
JOSUÉ DE CASTRO: FOME E REPERCUSSÕES SOCIAIS
}

\author{
Kátia Hale dos Santos ${ }^{1}$
}

\section{RESUMO}

O presente artigo tem como objeto o fenômeno da fome e suas repercussões sociais segundo o pensamento do maior estudioso brasileiro do assunto, Josué de Castro. O estudo da fome na produção intelectual do escritor é tomado, neste trabalho, como resultado de um confronto entre suas experiências pessoais e a realidade histórica da época. Detemo-nos diretamente no período correspondente ao desenvolvimentismo no Brasil, quando foi priorizado o investimento na indústria como principal atividade econômica para seu desenvolvimento, deixando, o governo, as atividades agro-rurais em segundo plano. As transformações pelas quais passou o Brasil naquele período histórico formaram o cenário para perpetuar a fome aqui e nos demais países em via de desenvolvimento.

PALAVRAS-CHAVE: Fome, Reforma Agrária, Política Social, Estrutura Social

\section{INTRODUÇÃO}

Pensar o presente e projetar o futuro sugere um inevitável "revisitar" do passado. Em um período da História em que se evidencia a fome no Brasil - com políticas articuladas em torno da principal bandeira de campanha à Presidência da República de Luiz Inácio Lula da Silva, o Programa Fome Zero e, depois, o BolsaFamília, principais responsáveis por sua reeleição e manutenção da sua popularidade no governo - examinaremos a fome sob uma perspectiva histórica, tendo como objetivo investigar os conceitos de fome e suas repercussões sociais relacionando-os ao

\footnotetext{
${ }^{1}$ Assistente Social pela Universidade Católica de Santos, Mestre em Serviço Social pela Pontifícia Universidade Católica de São Paulo. E-mail: katiahale@gmail.com

Revista Serviço Social \& Saúde. UNICAMP Campinas, v. X, n. 11, Jul. 2011
} 
pensamento do primeiro cientista brasileiro a mapear a fome no Brasil e no mundo Josué de Castro.

Delimitamos nossos estudos em torno de duas obras do autor: O Livro Negro da Fome (1960) e Sete Palmos de Terra e Um Caixão (1967), pois nelas estão condensados os conceitos de fome e suas repercussões sociais, objeto do nosso artigo.

\section{JOSUÉ DE CASTRO ENTRE HOMENS E CARANGUEJOS}

Em cinco de setembro de 1908 nasceu Josué Apolônio de Castro, filho de Manoel Apolônio de Castro e de Josepha Carneiro de Castro, na cidade do Recife. O pai de Josué veio com a família de Cabaceiras, Alto Sertão paraibano, fugindo das agruras sofridas em decorrência da grande seca de 1877. Era proprietário de terras e mercador de gado e de leite. Josepha Carneiro, também conhecida como "Dona Moça", era filha adotiva de senhores de engenho na zona da mata pernambucana e tornou-se professora no Recife. Segundo Rui Ribeiro de Castro, em sua tese "A dimensão populacional na obra de Josué de Castro" (2004):

Sua mãe era filha de criação de donos de engenho na zona da mata pernambucana, de modo que ele era fruto do sertão, da semi-aridez e do gado, e da mata úmida e açucareira. Quando tinha quatro anos, seus pais se separaram. O pai (Manoel de Castro) era um comerciante de gado e leite, proprietário de terras em Cabaceiras (PB), com pouca instrução formal e com uma situação financeira estável. A mãe (Josefa Castro, também conhecida como Dona Moça), apesar de origem mais aristocrática, era pobre (na época, mulher abandonada pelo marido não possuía direitos) e conseguia algum recurso através de aulas ministradas em sua casa para filhos de operários pobres, os quais pagavam pouco pelas aulas. $\mathrm{O}$ fato de ser filho de pais separados, único filho por parte de mãe e de ter tido 
uma infância com privações, ao lado de crianças que habitavam os mocambos erguidos nos mangues (mais habituados a lares desfeitos e pouco preocupados com certas convenções sociais), marcaram muito sua trajetória [...] Mais tarde - não obtivemos a data precisa e os motivos exatos - passou a residir com o pai, que financiou seus estudos, inclusive o curso superior de Medicina (CASTRO, 2004, 8, 137)

Pernambuco daquela época não apresentava diferenças consideráveis em relação ao restante do Nordeste brasileiro, estagnado economicamente e com sua gente sofrida. A situação da região se agravara em consequência das terríveis secas que se sucederam no final do século XIX. Só na grande seca de 1877 a 1879 morreram cerca de 300 mil pessoas. As secas continuavam se repetindo em 1888/ 1889 e 1898/1900, afetando a população trabalhadora do sertão. Com a produção paralisada e a economia em crise, só restava aos trabalhadores sertanejos desempregados a alternativa de migrarem para outras regiões do território brasileiro. Alguns buscavam a Amazônia e o Centro Sul, onde se desenvolviam respectivamente as culturas da borracha e do café, outros permaneceram no Nordeste, dirigindo-se para a região da Zona da Mata, onde esperavam encontrar trabalho e auxílio do governo para amenizar a fome trazida pelas secas. Das grandes levas de retirantes que enchiam de tristeza e fome as estradas do sertão, em caminhadas infindas rumo à Zona da Mata, nem todos alcançavam seu destino. Os que chegavam, deslumbrados com a beleza da cidade desenvolvida, formavam um numeroso exército de reserva da indústria da cana-de-açúcar e logo se apercebiam de que as grandes mansões e os carros que circulavam pelas metrópoles eram para poucos. A mão-de-obra quase gratuita do retirante também era utilizada nos melhoramentos urbanos, mas sua força de trabalho de quase nada valia, sendo os seus ganhos insuficientes para suprir suas necessidades básicas, o que incluía a alimentação. 
A saída era recorrer à vida nos manguezais ou à periferia das cidades, formando os primeiros grandes bolsões de miseráveis e desencadeando o processo de favelização.

No livro "Nordeste: aspectos da influência da cana sobre a vida e a paisagem do Nordeste do Brasil”, escreveu Gilberto FREYRE (1951):

Esse Nordeste da terra gorda e de ar oleoso é o Nordeste da cana-de-açúcar. Das casas-grandes dos engenhos. Dos sobrados de azulejo. Dos mocambos de palha de coqueiro ou de coberta de capim-açú. O Nordeste da primeira fábrica brasileira de açúcar - de que não se sabe o nome - e talvez da primeira casa de pedra-e-cal, da primeira igreja no Brasil, da primeira mulher portuguesa criando menino e fazendo doce em terra americana; do Palmares de Zumbi - uma república inteira de mocambos. O Nordeste que cai do Recôncavo ao Maranhão, tendo o seu centro em Pernambuco [...] Segundo documento oficial - Aspectos da Economia Rural Brasileira - há no Nordeste propriedades em que os trabalhadores iniciam os seus serviços com o romper do sol e só os deixam ao acaso, com pequenos intervalos para o almoço e para a merenda. E todo esse excesso de esforço físico dos trabalhadores de açúcar, dos cabras de engenho, dos negros da bagaceira, a despeito das condições de vida terrivelmente desfavoráveis: quase nus e minados por toda sorte de mazelas e vícios; morando em choupanas miseráveis. E não se deve esquecer o que é capital na explicação do muito que se encontra de inferior em proletariado de condições de vida tão à toa: a alimentação a um tempo imprópria e deficiente. Não só por erros tradicionais de dieta como pela necessidade de acomodarse o trabalhador a salários os mais reduzidos e a fontes de alimentação as mais escassas (FREIRE, 1951, p. 36, 255, 256 grifos do autor). 
Nesse cenário nasceu e cresceu Josué de Castro. A infância de nosso autor nos é revelada por ele mesmo, no prefácio de seu único romance, "Homens $e$ Caranguejos", de 1965, intitulado "Prefácio um tanto gordo para um romance um tanto magro”. Escreveu o autor:

A casa em que nasci tinha ao lado um grande viveiro de peixes, de caranguejos e de siris. Se não nasci mesmo dentro do viveiro, como os caranguejos, já com dois anos estava dentro dele. Escorreguei um dia no barro de suas margens e fui retirado de dentro de suas águas meio afogado. Daí em diante, mergulhar nas águas do mangue tornou-se um hábito. Mudei-me depois para outro bairro mais perto do rio. Fomos morar na Madalena, numa velha casa colonial de um só andar, com seis grandes janelas de frente (CASTRO, 2005, p. 14).

Foi no curso de Medicina pela Faculdade Nacional da Universidade do Brasil que Josué de Castro pôde, sob o aspecto biológico, conhecer o homem e compreender suas carências e necessidades. Essa foi a sua porta de entrada para o mundo da ciência. No início da década de 1930, Josué de Castro começou a clinicar em Recife, na área de medicina nutricional. Paralelamente à clínica, começou a trabalhar em uma fábrica, que o contratara com o objetivo de aumentar a produtividade de seus funcionários. Em 1932, após dois anos de trabalho, avalia e constata pela primeira vez o estado de penúria em que viviam os operários e a fome endêmica como sua real doença. Como resultado de seu trabalho, produziu o inquérito "As condições de Vida das Classes Operárias do Recife", primeiro inquérito do gênero realizado no país, em que são estabelecidas relações diretas entre a produtividade do trabalhador e sua alimentação, bem como são examinados suas condições de vida, seu tipo de moradia, seu salário e o quanto era investido na aquisição de alimentos. O inquérito identifica o salário recebido pelo 
trabalhador e o investimento em sua alimentação, constatando que os ganhos não supriam suas necessidades calóricas:

Um trabalhador necessita em média de 3.000 a 4.000 calorias diárias para suas despesas fundamentais e de trabalho. O regime que analisamos, possuindo apenas 1.645 calorias, é um regime insuficiente, que somente chega para cobrir os gastos do metabolismo mínimo individual no nosso clima sem margem para o gasto do trabalho. [...] Diante desta exposição fica evidente a péssima qualidade da alimentação operária, sendo seu regime impróprio sob todos os aspectos [quantitativo e qualitativo]. Só há uma maneira de alimentar-se pior do que esta; é não comer nada. É por isso que essa gente não fala em alimentar-se, mas em enganar a fome. [...] Por este estado de coisas, vê-se quanto é urgente a organização de um plano de combate à má alimentação que possa minorar os seus malefícios, produto de nossa defeituosa organização econômicosocial e da orientação unilateral que até hoje se tem dado, entre nós, aos objetivos de higiene pública (CASTRO, 1968, p.76-9).

O resultado do inquérito foi publicado em 1935, em Boletim do Ministério do Trabalho e, tendo forte impacto nos meios cultos da época, torna-se referência obrigatória para os estudos semelhantes sobre as condições de nutrição no país. A partir desse e de outros inquéritos realizados no Rio de Janeiro, São Paulo e outras localidades, constituem-se as bases para o surgimento do salário mínimo, instituído em 1940, sob o governo de Getúlio Vargas. Se desde o Brasil colônia a fome fazia parte da realidade nacional, foi na Revolução de 1930 e nas décadas subseqüentes que o tema entrou na pauta das preocupações do Estado, sendo Josué de Castro um dos responsáveis por esse intento. É nesse período que se estabelecem as novas relações de produção capitalista nos moldes urbano-industriais. Era preciso, então, reorganizar a 
produção e circulação de alimentos, para que fossem abastecidas as cidades e alimentados os trabalhadores. O êxodo rural aumentava assustadoramente no período da Revolução, ampliando também as filas do exército industrial de reserva, o qual necessitava acreditar, antes de rumar para as cidades, que lá existia uma estrutura que suprisse todas as suas necessidades básicas, o que incluía a alimentação.

O discurso de Vargas sobre as "benesses" da revolução incentivou o êxodo rural. A miséria, para aqueles que se dispunham a deixar os mais diversos cantos do país em direção às cidades onde se estabeleceram as indústrias, jamais os alcançaria ${ }^{2}$. Essa oferta de melhores condições de vida nas cidades fez com que Getúlio ficasse conhecido na História como "pai dos pobres". A institucionalização da fome pelo Estado brasileiro, inserida em interesses maiores, quais sejam, o de institucionalizar as novas formas de produção, sendo necessária a criação política que garanta a acumulação de capital pelos setores agroexportadores e industriais, classifica o Presidente como "mãe dos ricos".

O Estado passa a ser o maior interessado em promover a assistência aos trabalhadores da Revolução de 1930, tornando questão de Políticas Sociais as necessidades desses trabalhadores - aposentadoria, saúde, educação e alimentação. Dessa forma, os operários não são vistos como mercadoria escrava afastada por completo de suas necessidades humanas, ao contrário, são humanos cujas necessidades devem ser preenchidas para que possam ofertar sua força de trabalho, que passa a ser sua moeda de troca, portanto, uma mercadoria. Em decorrência desse panorama histórico são criadas as primeiras políticas sociais relacionadas ao trabalho e à alimentação. Se tais políticas não enfrentariam os problemas em sua totalidade,

\footnotetext{
${ }^{2}$ Vargas criou o Programa a Voz do Brasil em 1934, que posteriormente se transformou em a Hora do Brasil, no qual o presidente e seus ministros pronunciavam suas realizações e os avanços na Revolução de 1930.
} 
amenizariam seus efeitos. O processo de institucionalização da fome acontece sob forte determinação da Revolução Conservadora de 1930, tendo Josué de Castro muita responsabilidade sobre ela: Em 1935, Josué de Castro participou da idealização e execução do Serviço Central de Alimentação (SCA), do Instituto de Aposentadoria e Pensões dos Industriários (IAPI), considerado um marco na assistência alimentar do trabalhador, que se transformaria no futuro Serviço de Alimentação da Previdência Social (SAPS).

É na década de 1920 que surge a Previdência Social no Brasil, porém, como instituição privada, sem a participação financeira do Estado. Eram as Caixas de Aposentadoria e Pensões - CAPs -, arranjos feitos entre vendedores e compradores da força de trabalho. A Lei Eloy Chaves é promulgada em 1923, estabelecendo a Caixa de Aposentadoria e Pensões dos ferroviários, espalhando-se por outras categorias, ainda na década de 1920. O Instituto de Aposentadoria e Pensão dos Industriários foi o último a ser criado. Antes da Constituição de 1934, todas as categorias urbanas tinham os seus institutos, menos os industriários. Sua criação vem a reboque das transformações que se processavam em 1930. Foi tanta a dedicação à sua elaboração e execução, que se tornou um modelo de previdência social no Brasil, sofrendo alterações apenas em 1964. O Serviço Central de Alimentação foi o primeiro espaço regularizado pela revolução para tratar da questão alimentar e nutricional dos trabalhadores urbanos.

Josué de Castro aparece, então, intimamente ligado à criação das primeiras instituições públicas, participando de sua elaboração e da direção de algumas delas. Em 1940 funda a Sociedade Brasileira de Alimentação, com o objetivo de pôr em prática seu conhecimento teórico. O Serviço de Alimentação da Previdência Social (SAPS) é criado em agosto do mesmo ano, pelo Decreto no 2.478 , de cinco de fevereiro, pelo Ministério do Trabalho, Indústria e Comércio, para fazer frente ao decreto-lei que Revista Serviço Social \& Saúde. UNICAMP Campinas, v. X, n. 11, Jul. 2011 
estabelecia a obrigatoriedade da instalação de refeitórios nas empresas com mais de 500 funcionários. Josué de Castro torna-se diretor do SAPS em 1941, o que reforçou seu papel no processo de institucionalização das novas relações de produção daquele momento histórico. A criação desse serviço tem referência na teoria do círculo vicioso da doença, segundo o qual o trabalhador precisa ser alimentado para melhor produzir, ganhando melhores salários e se alimentando adequadamente.

Paralela à participação de Josué na formação da política pública alimentar, esteve presente no mundo acadêmico desde muito cedo. Foi professor catedrático de Antropologia da Universidade do Distrito Federal de 1935 a 1938 e, posteriormente, professor catedrático de Geografia Humana na Faculdade Nacional de Filosofia da Universidade Federal do Rio de Janeiro - UFRJ - de 1940 a 1964. Dessa forma, criou condições para pesquisar e aprofundar seus estudos sobre a fome. Na Faculdade de Medicina da Universidade do Brasil, onde ministrava aulas sobre alimentação e nutrição no Departamento Nacional de Saúde Pública - DNPS - teve condições de fundar o primeiro curso de Especialização em Nutrição. Em 1943 tornou-se catedrático da cadeira de Nutrição do curso de sanitaristas do Departamento Nacional de Saúde Pública, bem como idealizou e dirigiu o Serviço Técnico de Alimentação Nacional (STAN), vinculado à Coordenação de Mobilização Econômica. Este é o órgão por meio do qual o governo federal coordenava todas as atividades relacionadas aos assuntos econômicos nacionais, criado a partir do contexto da II Guerra Mundial. Voltada para a área de Tecnologia Alimentar, cabia ao STAN realizar pesquisas laboratoriais e experimentar novos métodos de conservação de alimentos. Em 1944, por iniciativa do STAN, criou no Rio de Janeiro o Instituto de Tecnologia Alimentar - ITA - que se propunha a aperfeiçoar o processo produtivo da indústria brasileira de alimentação. Em 1945, o STAN é substituído pela Comissão Nacional de Alimentação (CNA), que Josué 
de Castro passa também a dirigir até 1954. Era um órgão do Conselho Federal do Comércio Exterior, que tratava de dar um caráter mais permanente às atividades iniciadas pelo STAN: educação alimentar e assistência à indústria nacional de alimentos, no tocante ao aperfeiçoamento de tecnologia alimentar de base nacional. Entretanto, a CNA, criada em 1945, só seria regulamentada em 1951, pois perde importância no governo Dutra (1946 - 1951), sendo transferida para o âmbito do Ministério da Educação e Saúde, com menor poder de atuação. Efetivou-se no cargo de professor da Faculdade Nacional de Filosofia da Universidade do Brasil em 1947, por meio do concurso de cátedra de Geografia Humana, no qual defendeu a tese Fatores de localização da cidade do Recife: um ensaio de Geografia Urbana.

Dentre os inúmeros livros publicados, em 1946 publicou sua obra de maior repercussão, Geografia da Fome, a qual representa um momento importante nos estudos do autor e que marcou uma mudança em relação à produção anterior. Se, em seus primeiros escritos, a fome, a subnutrição e o problema alimentar apareciam como sinônimos, em Geografia da Fome, nosso autor explorou exatamente o eixo principal de suas formulações. Ao contrário dos enfoques fragmentados e pouco articulados entre si, ele propôs uma categoria que exprimisse a amplitude e a multidisciplinaridade da questão. Demonstrará a obra reorientações no pensamento do autor, relacionadas com sua trajetória pessoal e com as mudanças na conjuntura histórica do país naquele período. O livro denuncia, para o Brasil e para o mundo, o delicado e perigoso fenômeno da fome e os flagelos dela decorrentes. As duas obras referências do presente artigo estão orientadas sob o que poderíamos chamar de segunda fase do pensamento josuelino e são escritas nos anos 1950, durante o governo Juscelino Kubitschek. JK foi o presidente que ganhou a simpatia dos brasileiros ao anunciar um Plano de Metas que prometia "50 anos de progresso para o país em cinco anos de realizações". Um plano Revista Serviço Social \& Saúde. UNICAMP Campinas, v. X, n. 11, Jul. 2011 
que pretendia desenvolver os setores estratégicos, principalmente energia, transporte, indústria de base, alimentação e educação, sendo o grande desafio de JK a construção de Brasília e a transferência da capital federal para a cidade satélite, na região centro-oeste do país. A eleição de JK e seu plano de metas receberam apoio de Josué de Castro:

O Sr. Juscelino Kubitschek, quando candidato à suprema magistratura do país, apresentou um plano de desenvolvimento com metas definidas e estruturadas à base de estudos aprofundados [...] Vencido o clima de desassossego e hoje encontrando-se o país a caminho da paz e da tranquilidade, volta suas vistas e toda sua energia a fim de levar a efeito este plano que trará, certamente, os maiores benefícios para a coletividade brasileira. Deste plano de desenvolvimento econômico faz parte, essencialmente, a expansão e a nacionalização da indústria no Brasil [...] Daí o papel importante que têm a desempenhar, no próximo ano, as classes produtoras do setor industrial e a alta expressão do ato que se realizou ontem, da posse da nova Confederação Nacional das Indústrias (Josué de Castro: Perfis Parlamentares 52, p. 115 )

Para o presidente JK, somente pelo processo de industrialização e crescimento econômico o país alcançaria prosperidade e superaria seu atraso em relação às nações desenvolvidas. Segundo CARDOSO (1978), Juscelino acreditava que

[...] com o advento industrial, com o crescimento da indústria pesada, virá o aumento da riqueza, virá a prosperidade, que não atinja apenas grupos particulares, mas a sociedade inteira: todos que a compõem poderão beneficiar-se do progresso alcançado. (CARDOSO, 1978, p.94)

A busca da prosperidade, portanto, carregava a marca do social e, nesta, a de toda a coletividade. Também não existia para o presidente pobreza ou subdesenvolvimento que não pudessem ser superados, sendo o trabalho, não como 
categoria, mas como o ato de trabalhar, o principal condicionante para $o$ desenvolvimento de todas as regiões do país. O plano de desenvolvimento do país no governo JK, com foco na industrialização e na política externa, encontrou, segundo Miriam Limoeiro Cardoso, um momento adequado para sua execução:

A conjuntura internacional, mostrando as ambições expansionistas do comunismo, acrescida das especificidades da América Latina, em que ressaltam a explosão demográfica tornando crescente a dificuldade de elevação da renda per capita - e a politização, que os povos latino-americanos vêm experimentando cada vez mais acentuadamente, parecem estar a exigir o que Juscelino chama de "uma teoria dinâmica de desenvolvimento", em que a democracia seja preservada através do combate ao pauperismo. "Não nos enganemos: estamos vivendo, não apenas na América Latina, mas em todo o mundo, situações radicalmente novas, que exigem o estabelecimento de um novo sistema de relações entre os povos altamente industrializados e os povos subdesenvolvidos. Não é concebível que, diante da ameaça que representa para o Ocidente o comunismo internacional, as nações democráticas se mostrem incapazes de superar os erros do passado e de formular uma política de grandeza, que demonstre a capacidade de democracia de atender às necessidades da maioria esmagadora da humanidade, constituída por povos que ainda vegetam no limiar da civilização moderna" (fragmento de discurso de JK in CARDOSO, 1978, p. 99).

A Guerra Fria entre as duas grandes potências mundiais, EUA e União Soviética, e o temor constante de que o comunismo se espalhasse por todo o mundo - o que seria facilitado, na visão de JK e de outros intelectuais da época, inclusive Josué de Castro, pela possível ameaçadora tomada de consciência do estado de miséria em que viviam as populações dos países pobres do mundo - formava o quadro perfeito para a Revista Serviço Social \& Saúde. UNICAMP Campinas, v. X, n. 11, Jul. 2011 
implementação da política externa juscelinista, na qual as nações democráticas e ricas correriam em auxílio aos povos atrasados e inconformados com a desigualdade das suas condições materiais, preservando a democracia desses países, sua soberania e sua paz. Concordando com a visão de JK, Josué de Castro escreveu na obra "O Livro Negro da Fome":

Um dos fatores mais constantes e efetivos das terríveis tensões sociais reinantes é o desequilíbrio econômico do mundo, com as resultantes desigualdades sociais. Constitui um dos maiores perigos para a paz, como a tranquilidade da ordem, o profundo desnível econômico que existe entre os países economicamente bem desenvolvidos de um lado, e de outro lado os países insuficientemente desenvolvidos. Desnível que se vem acentuando cada vez mais, intensificando as dissensões sociais e gerando a inquietude, a intranquilidade e os conflitos políticos e ideológicos [...] Embora o desenvolvimento econômico de cada país deva constituir uma responsabilidade nacional é evidente que sem uma ampla cooperação internacional é muito difícil que este desenvolvimento se processe em ritmo desejável nos países pouco desenvolvidos, de forma a preservar o equilíbrio político e social do mundo (CASTRO, 1960, p.13-4, 58).

$\mathrm{O}$ estado de pobreza e miséria em que viviam os latino-americanos e demais pobres em todo o mundo ameaçava, segundo Josué de Castro, a paz e a ordem dos países que formavam o continente americano e dos demais países subdesenvolvidos. Para equilibrar a economia mundial, atuou a "cooperação internacional", que se traduziu, durante o nacional desenvolvimentismo, em empréstimos financeiros a juros altíssimos e na instalação de transnacionais no país, as quais fincaram sua estrutura no país com inúmeros benefícios fiscais. 
JK necessitava encontrar uma teoria "científica" que explicasse e fortalecesse seu discurso e seu Plano de Metas. O conjunto de ideias que caracterizou o Nacional Desenvolvimentismo foi originado da Comissão Econômica para a América Latina (CEPAL), órgão vinculado à Organização das Nações Unidas e do Instituto Superior de Estudos Brasileiros (ISEB).

A proposta da CEPAL teve como eixo as próprias experiências do Brasil e de alguns países latino-americanos. Em linhas gerais, a CEPAL, através de economistas como Raul Prebish e Celso Furtado, propôs uma nova interpretação sobre as relações entre os países de capitalismo avançado e os países latino-americanos subdesenvolvidos, por meio da qual a ênfase foi dada na necessidade de superar a visão dos países periféricos como fornecedores de matérias-primas aos países desenvolvidos e compradores de produtos industrializados. Celso Furtado foi o principal teórico e divulgador das teses cepalinas no Brasil, basicamente em relação à crítica da teoria neoclássica sobre o desenvolvimento e à lei das vantagens comparativas do comércio internacional. Os teóricos da CEPAL procuravam demonstrar que o comércio entre os países periféricos e os países desenvolvidos fundamentava-se em um sistema de trocas desiguais, cujos valores de matérias-primas eram rebaixados pelas economias centrais, enquanto os produtos manufaturados - vendidos pelos países desenvolvidos - eram mantidos em níveis altos. Dessa forma, tornava-se fundamental a substituição desse modelo nos países subdesenvolvidos, substituindo-o pela implantação da indústria de base e de bens duráveis, alcançando, assim, o crescimento econômico, e diminuindo o desequilíbrio entre os países e sua principal consequência: a miséria, que encontrava na fome seu pior traço. A teoria econômica cepalina foi fortemente influenciada pelo economista Gunnar Myrdal. Em sua obra Teoria Econômica e Regiões 
Subdesenvolvidas (1960), Myrdal explicou que o equilíbrio estável era uma falsa analogia:

O equilíbrio estável é uma dessas premissas irrealistas. Em sua forma menos complicada, envolve as noções de que toda perturbação provoca reação dentro do sistema, dirigida no sentido de restaurar novo estado de equilíbrio, e a ação e a reação devem ocorrer no mesmo e único espaço-tempo. Um sistema econômico que não se encontra em estado de repouso está sempre, por essa razão, a mover-se para o equilíbrio, embora não o faça, necessariamente, de modo imediato. Admitese também, geralmente, que toda nova modificação primária, adicionada ao fato de o sistema não repousar em permanente equilíbrio, virá abalar a posição de estabilidade virtual, na direção da qual se está movendo. Implícita na noção de equilíbrio estável, e preservada mesmo em suas formas de maior relatividade, está a ideia de que, quando a mudança provoca como reação outras mudanças, essas, secundárias, são dirigidas em sentido oposto ao da mudança primária (MYRDAL, 1972, p. 27-8).

Em outras palavras, por definição, os países subdesenvolvidos tinham estrutura econômica desequilibrada e seu equilíbrio não devia ser um fim. O objetivo, segundo o autor, era de atingir o desenvolvimento a partir de um processo de industrialização impulsionado por desequilíbrios. A contribuição essencial de Myrdal estava relacionada ao enfoque dado à dinâmica centro versus periferia e, para entender o subdesenvolvimento de um país, é preciso inseri-lo nesse contexto. A partir desta ótica o desenvolvimento nunca será igual entre as regiões; encontrar-se-ão desequilibradas porque visam o favorecimento das economias mais desenvolvidas.

Em 14 de julho de 1955 foi criado, oficialmente, o Instituto Superior de Estudos Brasileiros (ISEB), por decreto legalizado pelo presidente então em exercício, 
João Café Filho. Porém, sua gestação iniciara em 1953, sob o segundo governo Vargas, quando se formou o grupo Itatiaia - que congregava intelectuais do Rio de Janeiro e de São Paulo, os quais se reuniam na sede do Parque Nacional de Itatiaia - com a finalidade de discutirem os problemas da nação. A existência do grupo Itatiaia foi efêmera, já que conflitos ideológicos estavam em jogo entre seus membros: de um lado situavam os intelectuais de formação filosófica marcados pelo integralismo, os quais se manifestavam a favor da abertura do mercado econômico brasileiro e, de outro lado, estavam os economistas diretamente ligados ao governo Vargas, os quais lhe prestavam assessoria. No ano de 1953 os intelectuais cariocas fundam o Instituto Brasileiro de Economia, Sociologia e Política (IBESP), com o objetivo de estabelecer uma entidade privada como centro de estudos especializados na pesquisa e planejamento de questões ligadas à realidade socioeconômica nacional. Grande parte de seus membros compunha o quadro de funcionários do Estado. Hélio Jaguaribe assumiu, no IBESP, o cargo de Secretário Geral, fazendo também parte do quadro do Instituto, além de economistas e sociólogos radicados no Rio de Janeiro, o paulista Roland Corbisier. Nessa entidade, o grupo editou cinco volumes dos Cadernos do Nosso Tempo ${ }^{3}$, entre 1953 e 1956, dando início a uma formulação teórica de cunho nacionalista que preconizava a defesa e consolidação do capitalismo brasileiro. Café Filho, ao contrário do que temiam os

\footnotetext{
3 Publicados entre 1953 e 1956, totalizando cinco volumes que vieram a marcar época, tais cadernos tiveram como vértice as discussões do Grupo de Itatiaia e consolidaram-se coma criação do IBESP (Instituto Brasileiro de Economia, Sociologia e Política). Mesmo após a criação do ISEB, continuaram a ser publicados por um breve período. Os trabalhos publicados nos Cadernos de Nosso Tempo geralmente não contêm citações e/ou preocupações acadêmicas, são textos de construção e combate que denotam a preocupação essencial dos autores: influir decisivamente na realidade brasileira. Entre os temas abordados, estão: o Estado, o pensamento social no Brasil, os agentes e fenômenos políticos, a economia, posição na geopolítica, a condição do negro etc. Em textos concebidos individual ou coletivamente os autores abordam os problemas latentes da sociedade brasileira - naquela década de 50 - e, mais que diagnosticar, por vezes, apresentam sugestões para equacionar os problemas. Embora mantivessem um caráter engajado e não-acadêmico, alguns textos apresentam contribuições teóricas a questões que viriam a fazer parte da agenda teórica do período imediatamente posterior, como: populismo, patrimonialismo, caráter privatista do Estado, nacionalismo, colonialismo, desenvolvimento, subdesenvolvimento, condição do negro, etc.
} 
membros do ISEB - já que sua posse fora sustentada pelos antigetulistas -, não ameaçou extinguir o Instituto. Ao contrário, procurou oficializá-lo pelo Decreto $\mathrm{n}^{\mathrm{o}}$. 57608, como entidade vinculada ao Ministério da Educação - cujo ministro era Cândido Mota Filho - concedendo-lhe autonomia administrativa e liberdade de pesquisa e opinião, ainda que com dotações orçamentárias bastante incertas e limitadas.

Extinto em 1964 com o golpe militar, o ISEB reuniu intelectuais como Roland Corbusier, Álvaro Vieira Pinto, Guerreiro Ramos, Hélio Jaguaribe, Nelson Werneck Sodré, entre outros. Desde seus primeiros anos, além da publicação de livros e da realização de seminários e debates públicos, o ISEB se notabilizou por oferecer cursos regulares a oficiais das Forças Armadas, empresários, sindicalistas, parlamentares, funcionários públicos, burocratas e técnicos governamentais, docentes universitários e do ensino médio, profissionais liberais, religiosos, estudantes, etc., difundindo seus conceitos nacionalistas e formando quadros para o Estado e para a sociedade brasileira. Distinguindo-se de uma instituição acadêmica foi, precipuamente, um centro de formação política e ideológica ${ }^{4}$, de orientação democrática e reformista. Pode-se afirmar que o ineditismo da experiência isebiana consistiu no fato de intelectuais, de distintas orientações teóricas e ideológicas, reunirem-se não apenas para debater e refletir sobre os dilemas e os problemas cruciais da realidade brasileira. De forma deliberada, o Instituto foi criado para servir de instrumento para uma ação eficaz no processo político do país. Segundo Toledo (1977):

A necessidade de forjar uma ideologia que promova e incentive o desenvolvimento - presente em todos os "isebianos históricos" (G. Ramos, C. Mendes. H. Jaguaribe, R. Corbisier, Vieira Pinto, como exceção de N. W. Sodré) - se explicará em função das

\footnotetext{
${ }^{4} \mathrm{O}$ termo ideologia, discutido no interior do ISEB, não se refere ao sentido marxista de "ideologia como falsa consciência", mas como uma contribuição para racionalizar o surto de desenvolvimento que se processava no país e elaborar uma teoria que o promovesse e o incentivasse.
}

Revista Serviço Social \& Saúde. UNICAMP Campinas, v. X, n. 11, Jul. 2011 
possibilidades contidas no atual processo histórico das nações subdesenvolvidas onde já se instalaram efetivas condições para aquele processo de desenvolvimento. Muito longe da arbitrariedade e do idealismo estaria o projeto isebiano, afirmam estes pensadores. A ideologia do desenvolvimento é necessária porque atualmente se tornou possível constituí-la (TOLEDO, 1977, p. 35-6)

Segundo os referidos teóricos, tornava-se possível constituir a ideologia do desenvolvimento, pois a estrutura econômica do país - predominantemente agrária $^{5}$ e exportadora de produtos primários - convertia-se, naquele momento, em um crescente processo de industrialização e consequente urbanização e aumento do consumo. O país estava se modernizando e rompendo com estruturas conservadoras e obsoletas. À grande potência Brasil era chegada a hora de cumprir seu destino rumo ao desenvolvimento, "a fim de ser um grande império poderoso e forte, e não simples terra de plantação" (CARDOSO, 1978, p. 242).

Josué de Castro não era associado do ISEB, porém, mantinha estreito relacionamento com a instituição, comungando com muitos de seus conceitos e ideias. A possibilidade de a nação brasileira manter-se harmonicamente envolvida e unida sob um mesmo interesse, qual seja, o progresso do país e, consequentemente, o fim da fome, era interesse do nosso autor. Vale dizer, ainda, que Josué de Castro não era contrário aos fundamentos da sociedade capitalista e a existência da sociedade cindida em classes sociais, ou mesmo se opunha à propriedade privada dos meios de produção, mas se

\footnotetext{
${ }^{5}$ Em 1950, 10 milhões de brasileiros dedicavam-se à agropecuária, de quem mais 20 milhões dependiam. $\mathrm{Na}$ cidade, ativos, no comércio, nos serviços e nas indústrias, concentravam-se outros 21 milhões, ganhando salários baixíssimos. Viviam, portanto, $60 \%$ da população nas cidades e $40 \%$ nas áreas urbanas. O produto bruto nacional não ultrapassa sete bilhões de dólares e a renda per capita era de 137 dólares.

Revista Serviço Social \& Saúde. UNICAMP Campinas, v. X, n. 11, Jul. 2011
} 
confrontava com certos aspectos geradores de desigualdades sociais que impediam a todos colherem os frutos de um desenvolvimento econômico equilibrado.

É preciso antes de tudo trabalhar para extirpar do pensamento político contemporâneo esta ideia errônea da economia considerada como um jogo em que alguns devem sempre perder para permitir a outros sempre ganhar. É preciso fazer da economia um instrumento de distribuição equilibrada dos bens da terra, a fim de que em nosso tempo, já não se possa aplicar a esta ciência a definição amarga que lhe dera Karl Marx no século passado, quando falava das ciências das misérias humanas (CASTRO, 1960, p. 76-7).

Esclarecemos que as concepções desenvolvimentistas, encontradas na época entre parte dos intelectuais e do presidente brasileiro, concordavam com a teoria econômica de Lord Keynes, o qual acreditava que maximizando a produtividade da mão-de-obra e do capital, chegar-se-ia a promover a generalização do progresso e da riqueza. Esta última, por sua vez, seria distribuída automaticamente, pela força que Adam Smith chamava de "a mão invisível" que, numa economia liberal do "laissezfaire", se ocuparia de promover o equilíbrio econômico do mundo. A Escola de Manchester garantia que, pelas especializações econômicas das classes e dos países, toda a humanidade se beneficiaria do aumento da riqueza e chegaria ao reino de abundância universal.

Josué de Castro não era adepto da teoria keynesiana. Sua visão concorda com a da justiça social da Igreja, a qual discursava, pelo desenvolvimento mantido sob controle do Estado, o qual tinha a obrigação de melhor distribuir os bens (desde que mantido o direito natural da propriedade), promover a paz social e, consequentemente, o afastamento de ideais revolucionários comunistas. Relacionando a fome com a questão desenvolvimentista, Josué de Castro afirmou que não havia como negar a fome como um produto direto do subdesenvolvimento e que o subdesenvolvimento não era um fatalismo provocado pela força da natureza, mas um acidente histórico provocado pela força das circunstâncias, pelas mãos dos homens.

Se assim o era, o que fazer para acabar com o subdesenvolvimento das regiões pobres brasileiras, em especial o Nordeste do país? Qual a proposta do autor 
para o desenvolvimento da região Nordeste, área onde se concentrava o que Josué de Castro denominava de latifúndio feudal ${ }^{6}$ ? Para a região, nosso autor propõe uma reforma agrária

[...] que mereça de fato esse nome. Não a reforma agrária baseada em mera colonização de terras devolutas, a qual não passaria de um conjunto de medidas inócuas, deixando intocado o deplorável regime de terras imperante na região. Não a reforma agrária desejada por certos líderes ruralistas, que consistiria em desapropriar terras mediante a indenização prévia em dinheiro pelo seu valor venal no mercado imobiliário; mas sim a reforma agrária apoiada na desapropriação por interesse social, que retalhe os latifúndios improdutivos; que dê terra a quem dela necessite para viver com decência; que estipule novas e mais humanas bases de arrendamento; que regule os contratos de trabalho, fixando níveis salariais adequados; que cuide da assistência técnica e financeira aos pequenos produtores; que, em suma, liquide definitivamente os odiosos privilégios que ainda hoje enfeudam a propriedade da terra no Nordeste (CASTRO, 1967, p. 185).

Uma reforma agrária concebida como um processo de revisão das relações jurídicas e econômicas entre os que detinham a propriedade agrícola e os que trabalhavam nas atividades rurais, objetivando a tornar o rendimento da exploração da propriedade agrária mais elevado e, principalmente, melhor distribuído em benefício de toda a coletividade rural.

Não sem tempo, lembremos que o método geográfico adotado por Josué de Castro encontra seu fundamento na geografia humana de Vidal de La Blache e da escola

\footnotetext{
${ }^{6}$ Cabe dizermos que Josué de Castro não levou em consideração ao afirmar que o Brasil fora colonizado sob o regime feudal, que o regime de propriedade colonial em muito se diferenciava do regime feudal europeu. No feudalismo não existia uma produção exclusivamente voltada para o mercado externo como no sistema colonialista, a que o Brasil foi submetido desde os seus primórdios. No sistema feudal a terra servia praticamente para a própria subsistência de seus arrendatários.
}

Revista Serviço Social \& Saúde. UNICAMP Campinas, v. X, n. 11, Jul. 2011 
possibilista, na qual é possível compreender o homem na sua relação com a terra, sendo esse um agente capaz de mostra-se forte e modificar o meio em que vive, compondo, assim, o espaço humanizado. Decorrente dessa análise, nosso autor percebeu a possibilidade de entender a história das populações atingidas pela fome identificando seus determinantes. Se as regiões de fome no Brasil e no mundo são produtos das ações dos seres humanos, seria possível reverter essa calamidade.

Na obra O Livro Negro da Fome escreveu que "a verdade é que em medicina, como no campo das ciências sociais ou geográficas, cada vez mais devemos ser prudentes ao falarmos em determinismo, desde que mais consentâneo se apresenta o conceito de possibilismo, ou seja, da ação de fatores que possibilitam o aparecimento de determinados fenômenos, quer biológicos, quer sociais” (CASTRO, 1960, p. 19). Demonstrou nesta obra que mais de $66 \%$ da população mundial vivia em estado de fome crônica por imposição do pauperismo e da miséria econômica, sendo essa a causa da fraqueza e do desgaste biológico que inferiorizam os grupos mais pobres em comparação aos grupos mais ricos, bem alimentados e sadios. A desigualdade econômica em que viviam os humanos nos países subdesenvolvidos - os 19 países mais ricos, os quais contavam com apenas $16 \%$ da população do mundo, usufruíam mais de $70 \%$ da renda mundial, em contraste com os 15 países mais pobres, onde viviam mais de $50 \%$ do efetivo humano, recebiam menos de $10 \%$ da renda mundial - possibilitava a geração de fomes específicas (a fome de proteína é apontada como a principal) e preparava o terreno para manifestação de doenças.

Nosso autor travou debate contra as concepções deterministas de sua época quanto às análises do Nordeste brasileiro. Enquanto seus opositores defendiam que a tragédia presente no Nordeste era expressão exclusiva do duro clima sob o qual viviam aquelas populações, moldadas pela natureza a sua volta, concluindo-se que o flagelo da 
fome era mais intenso no sertão seco do que na zona da mata úmida - dado que os índices pluviométricos eram maiores do que no sertão - Josué provou, por meio de averiguação empírica, justamente o contrário. No sertão seco a fome esporádica acontecia nos tempos de seca, mas no trecho litorâneo ela era constante. Para analisar o fenômeno da fome, o autor identificou dois Nordestes, o Nordeste Oriental ou Marítimo e o Nordeste Ocidental ou Central:

São estes dois Nordestes tradicionalmente mais conhecidos como o Nordeste do açúcar e o Nordeste das secas, porque num deles tudo sempre girou em torno da economia da cana, noutro o que sempre marcou sua existência foi o tremendo drama de suas secas periódicas, a trágica história do seu clima incerto e inclemente. A verdade é que foi realmente o clima que delimitou os dois Nordestes. Enquanto no Nordeste Oriental, próximo da costa marítima, o clima é úmido, com uma grande abundância e regularidade de chuvas, no Nordeste Central, o clima é seco, as chuvas são escassas e, principalmente, muito irregulares, imprimindo um facies semiárido à região [...] Nestes dois quadros naturais tão diferentes se formaram também duas sociedades distintas, embora complementares, tanto em sua economia como em sua história [...] Não encontramos em toda a área do Nordeste um só e mesmo tipo de fome dizimando as suas populações. Enquanto na área do Nordeste açucareiro grassa um tipo de fome crônica e endêmica, o que nós encontramos no sertão são as epidemias de fome aguda, que aparecem nos períodos de seca (CASTRO, 1967, p. 38-9, 42).

Se o Nordeste Central foi marcado pelas secas, o Nordeste marítimo foi marcado pela exploração monocultora latifundiária da cana-de-açúcar. Josué de Castro já havia deduzido nos anos 1930, por meio do já mencionado inquérito sobre as condições alimentares dos trabalhadores da região da zona da Mata e de suas famílias, 
que aquela população sofria com a deficiência de alguns alimentos; todavia responsabilizou o atraso da região às péssimas condições em que vivia esta população de famintos que, não se alimentando e não produzindo o suficiente, não ganhava para as despesas com alimentação, acabando por prejudicar também o desenvolvimento local e do país. Se em seus estudos anteriores o determinante do subdesenvolvimento foi a fome, o autor interverte essa leitura ao perceber que a fome era causada pela ação humana naquele espaço, onde a produção era organizada para atender as necessidades de acumulação do capital dos grandes latifundiários monocultores e exportadores da cana-de-açúcar, não permitindo os proprietários a produção e a cultura de alimentos essenciais para a saúde e o desenvolvimento da população. Segundo o autor, esse quadro havia sido pintado há séculos:

[...] não se pode acusar de descabido exagero a famosa frase do escritor Pero Vaz de Caminha, autor da primeira carta sobre estas terras do Brasil, de que a terra é em tal maneira dadivosa que, em se querendo aproveitar, dar-se-á nela tudo. Infelizmente, não se quis. Não o quis o colonizador português. De nada valeram as grandes possibilidades naturais que a terra oferecia, pois que foram malbaratadas e inteiramente desaproveitadas em sua capacidade potencial de fornecer alimentos às populações regionais. Descobrindo cedo que as terras do Nordeste se prestavam maravilhosamente ao cultivo da cana-de-açúcar, os colonizadores sacrificaram todas as outras possibilidades da terra ao exclusivo cultivo dessa planta. Aos interesses de sua monocultura intempestiva, destruindo quase que inteiramente o revestimento vivo, vegetal e animal da região, subvertendo por completo o equilíbrio ecológico da paisagem e entravando, por todos os meios, quaisquer tentativas de cultivo de outras plantas alimentares, degradando desta forma ao máximo, os recursos alimentares da região. Esta influência nefasta da cana sobre as condições da alimentação regional não Revista Serviço Social \& Saúde. UNICAMP Campinas, v. X, n. 11, Jul. 2011 
se fez principalmente pela ação direta da cana sobre o solo, mas sim, por sua ação indireta, através do sistema de exploração da terra, que a economia açucareira impôs: o sistema da exploração monocultura e latifundiária (CASTRO, 1967, p. 44-5).

Segundo o autor, foram feitas tentativas no decorrer da História para mudar o regime de utilização das terras no litoral nordestino, os quais fracassaram em sua origem. A paisagem de miséria alimentar, como a pior face da miséria que acompanhava há séculos a população da região, perdurava, "apesar dos enormes progressos realizados na indústria do açúcar com a instalação das grandes usinas modernamente equipadas e apesar de todos os esforços do governo federal em ajudar a economia da região" (CASTRO, 1967, p.55). Sobre o sertão Nordestino, Josué afirmou que população detinha hábitos alimentares relativamente adequados para aquele domínio clímato-botânico, sendo o flagelo da fome esporádico e relacionado aos períodos de secas.

Se o sertão do Nordeste não fosse exposto às secas periódicas, ou mesmo sofrendo esse flagelo, se a sua economia se tivesse consolidado de forma a garantir à sua população um poder aquisitivo razoável, estou certo que o sertão do Nordeste não ficaria entre as áreas de fome do continente americano (CASTRO, 1967, p. 57).

$\mathrm{O}$ autor não subestima a importância dos fatores climáticos para o desenvolvimento do Nordeste, mas sustenta que a fome é a manifestação biológica de um problema social e econômico. No sertão, a alimentação à base de milho - como em quase em toda a América Latina - diferencia-se pelo consumo conjunto de proteínas oriundas do leite, da carne de gado vacum e do gado caprino. Como cedo foi verificada pelos colonizadores a pouca serventia da região para a agricultura, desviou-se a 
atividade do colono sertanejo para a pecuária. Segundo Josué de Castro, "a criação de gado vindo de Portugal ou do Arquipélago do Cabo Verde, o qual se aclimatava muito bem neste ar seco e saudável e se desenvolvia maravilhosamente nas suas pastagens naturais, formadas de várias espécies de gramíneas” (CASTRO, 1967, p. 63). O sertanejo pôde também criar o gado caprino, já que o animal adaptava-se ainda melhor ao ambiente que o gado vacum, era mais resistente aos períodos de seca e menos exigente em relação aos pastos. O sertanejo se constituiu numa espécie de vaqueiro e agricultor, um plantador de produtos para sua subsistência e de sua família. Um semeador em pequena escala "de milho, feijão, fava, mandioca, batata-doce, abóbora e maxixe, plantados no vales mais humosos, nos baixios, nos terrenos de vazante, como culturas de horta e jardim. Pequenas abóbadas de verdura que os senhores de engenho do brejo, plantadores de extensíssimos canaviais sempre olharam com desdém, chamando depreciativamente a este tipo de policultura do sertanejo, de roça de matuto" (CASTRO, 1967, p. 66). Tinha o sertanejo, dessa forma, e fora dos períodos de seca, uma alimentação equilibrada e que em muito superava o regime alimentar da população moradora na zona da mata.

Nosso autor afirmou ainda que a causa da fome nos períodos da seca estava menos ligada ao clima e mais à estrutura social reinante, à organização econômica defeituosa e à "proletarização progressiva de sua população, cuja produtividade é mínima e está longe de permitir a formação de qualquer reserva com que seja possível enfrentar os períodos de escassez, os anos de vacas magras, mesmo porque no Nordeste já não há anos de vacas gordas" (CASTRO, 1967, p. 93). Para acabar com a fome no sertão nordestino, seria necessário findar com o regime de arrendamento, da parceria e da meação, no qual o agricultor ficava com uma parte ínfima da produção, com a qual 
podia se alimentar e também a sua família, nunca sobrando para fins de comercialização ou às reservas para os tempos de seca.

Percebemos que o combate teórico contra o determinismo, levado a cabo pelo médico pernambucano, possibilitou a identificação de agentes históricos causadores do flagelo da fome e afastou a tese de que o povo nordestino estava, invariavelmente, condenado a viver na penúria ou a migrar para longe dessa terra tão inóspita. Josué de Castro não isolou os fatores biológicos, ao contrário, estabeleceu suas conexões com o social, o econômico e o político.

Sua leitura sobre o fenômeno da fome também nos revelou "dois Brasis", um arcaico e um moderno, sendo que a manutenção de esquemas ultrapassados de exploração da terra no Brasil arcaico gerava a fome, a qual incapacitava o homem física e psicologicamente, impedia sua produtividade e dificultava a promoção da unidade nacional, desejo maior do autor e promessa da política nacional desenvolvimentista. Se por um lado, ao localizar a fome como problema provocado pelo homem, Josué apresentou uma barreira para a transformação da realidade nacional e concretização de seu desenvolvimento, por outro lado, já não existiam obstáculos "naturais" para acabar com a fome, e o país poderia alcançar o progresso que tanto almejava. Sua viabilidade dependia somente da intervenção planejada do Estado e da cooperação dos "homens de boa vontade".

Quanto a política implementada no sertão nordestino no governo JK, as condições de produção e de trabalho não passaram por uma transformação expressiva, ao contrário, perdurou o regime de arrendamento, da parceria e da meação, sendo que, em qualquer modalidade, o latifundiário exigia contratos de curta duração, renovandoos em bases cada vez mais vantajosas, dada a tendência da valorização de suas terras. Josué de Castro identificou não só a infraestrutura agrária superada como motivo do Revista Serviço Social \& Saúde. UNICAMP Campinas, v. X, n. 11, Jul. 2011 
subdesenvolvimento do sertão, mas também os processos de distribuição da produção agrícola, com sua rede interminável de intermediários e atravessadores, que, no processo de industrialização do Nordeste, foi percebida pelo autor como mais um agravante para acirrar a fome eterna do povo sertanejo.

Comprometido com a causa dos famintos e excluídos, Josué de Castro fundou em 1957, em Paris, juntamente com Abbé Pierre e Padre Joseph Lebret, entre outras personalidades, a Associação Mundial de Combate à Fome. Em 2 de setembro de 1957, foi fundado o escritório brasileiro no Rio de Janeiro. Destacavam-se como planos de atuação da ASCOFAM no Brasil: um plano de combate às endemias do Nordeste através da assistência alimentar em colaboração com o Departamento Nacional de Endemias Rurais, um plano de enriquecimento artificial dos alimentos em colaboração com a Legião Brasileira de Assistência e um plano de expansão de produtos de proteínas através da instalação de grandes indústrias de rações balanceadas para toda a espécie de animais de criação, partindo de matérias-primas regionais. A respeito do plano de expansão de proteínas foi elaborado o estudo Proteínas para a América Latina, interessante pesquisa sobre as condições alimentares na América Latina, cujo objetivo foi o de servir de projeto piloto. A preocupação com a expansão e o consumo de proteína na América Latina procedia, já que o consumo médio dos produtos de fonte de proteína animal (carne, peixe, leite, queijo e ovos) era um dos mais reduzidos do mundo. O consumo de carne não alcançava a 30 quilos por habitante e por ano e o consumo de leite, em muitas regiões da América Latina, era praticamente nulo, pois não atingia a oito litros por ano e por habitante. (1960, p. 142). No Brasil, a F.A.O. (Organização das Nações Unidas para Alimentação e Agricultura), estimava que o consumo humano de proteínas era da ordem de 54 gramas/dia por habitante, sendo 17 gramas de origem animal, o que indicava 
quantidade insuficiente, uma vez que se deveria dispor de 70 a 80 gramas de proteínas por habitante, das quais 30 a 40 gramas de origem animal (1960, p. 146). Era possível verificar o consumo de proteína relacionado à região geográfica e à renda da população, já que em 1956, a renda per capita era da ordem de Cr\$12.000, regiões há que em que baixa a Cr\$ 3.400 (Nordeste Ocidental), a Cr\$5.300 e Cr\$ 5.500 no Nordeste Oriental e no Leste Setentrional e a Cr\$ 8.500 no Centro-Oeste; somente nas regiões Norte (Cr\$14.600), Sudeste (Cr\$18.100) e Sul (Cr\$12.900) verificavam-se médias superiores à nacional, havendo, entretanto, dentre elas, muitas áreas de baixa renda $(1960$, p. 146).

Podemos afirmar que a vida de Josué de Castro se confundiu com a luta travada por ele para pôr fim à fome que assolava $2 / 3$ da população de todo o planeta, sendo diversos os papéis desempenhados pelo autor na tentativa de combater o fenômeno da fome no Brasil e no mundo. Sua maior bandeira, "a reforma agrária", não foi levada a efeito no Brasil, permanecendo o modelo econômico dominante: a concentração de terras (o latifúndio), os desníveis de renda, a sujeição aos interesses externos e a fome, acompanhada de todas as mazelas decorrentes do fenômeno.

Em 1962 foi designado, pelo então presidente João Goulart, embaixadorchefe da delegação do Brasil junto à ONU, em Genebra, e em 1963 renunciou ao mandato de deputado federal, já que permanecia à frente da ASCOFAM e também foi designado para exercer as funções de representante no Brasil junto ao Conselho de Administração da Organização Internacional do Trabalho (OIT), também em Genebra. Em 1964, o regime militar se institucionalizou com o Ato Institucional no.1, impondo a cassação dos direitos políticos de Josué de Castro, entre outros intelectuais. No mesmo ano, a convite da ONU, tornou-se membro do Instituto de Formação Humana e Pesquisa da ONU para tratar dos assuntos sobre a fome. Impedido de voltar ao Brasil e Revista Serviço Social \& Saúde. UNICAMP Campinas, v. X, n. 11, Jul. 2011 
vivendo em Paris, deu continuidade à atividade docente, aos escritos sobre o fenômeno da fome e a participar de instituições relacionadas ao tema. Morreu em Paris, em setembro de 1973 .

\section{CONSIDERAÇÕES FINAIS}

Ao aportarmos na conclusão desse artigo, não poderíamos deixar de observar a tendência dos brasileiros a negligenciar a produção intelectual de grandes nomes da ciência brasileira e internacional anterior a nossa época, principalmente quando ela destoa das teorias relacionadas à ideologia dominante e à estrutura social vigente. O país da desigualdade trata discriminadamente os intelectuais que não estão na "moda" e que não comungam da ideologia do Estado. A cada geração, a vida intelectual no Brasil parece começar do zero e o apetite pela produção recente dos países "avançados" muitas vezes tem como avesso o desinteresse pelo trabalho da geração anterior, tendo como consequências a descontinuidade da reflexão, a interrupção do processo de construção do conhecimento - da ciência - e a falta de perspectiva para solucionar as múltiplas faces da questão social, entre elas, a fome. Sim, porque estudar o pensamento e a ação de homens públicos, de cientistas e de políticos que dedicaram a vida enfrentando resistências e perigos na tentativa de construir uma sociedade mais justa é uma das formas das quais devemos lançar mão para a construção do futuro.

Observamos a preocupação constante de Josué de Castro com o empobrecido e espoliado Nordeste brasileiro, região onde nasceu e cresceu, todavia, verificamos sua preocupação com a fome dos povos dos mais diversos países e continentes, encarando a humanidade como única e heterogênea. Se, por um lado, nosso autor preocupou-se em individualizar os casos e os problemas com o método geográfico, conciliando medidas que se ajustem em níveis locais e regionais, sem pretender um único remédio para 
territórios, povos e culturas distintas, por outro, demonstrou que muito tem em comum a história dos povos famintos de todo o mundo. A visão de totalidade de Josué de Castro não se expressa apenas na análise da interdependência dos fatos e fenômenos, mas também na concepção geográfica e no desejo de construir um só mundo, heterogêneo em suas diferenças, mas homogêneo em suas aspirações de bem-estar, de paz e de um mundo sem fome.

Josué de Castro é referência para o debate histórico sobre o fenômeno da fome e da miséria no Brasil e no mundo. Mesmo não sendo reconhecido o seu legado neste país em constante recolonização, segue como exemplo de compromisso público e de abrangência intelectual em torno da temática da fome. Se a academia tentou enterrálo e os intelectuais brasileiros da atualidade o desconhecem, ele foi lembrado pelo movimento mangue Pernambuco na música de Chico Science, com a qual encerramos nosso artigo:

Posso sair daqui para me organizar/ Posso sair daqui para desorganizar /Da lama ao caos /Do caos à lama/ Um homem roubado nunca se engana/ $O$ sol queimou, queimou a lama do rio/ Eu vi um chié andando devagar/Vi um aratu pra lá e pra cá/ Vi um caranguejo andando pro sul/ Saiu do mangue, virou gabiru/ Oh Josué eu nunca vi tamanha desgraça/ Quanto mais miséria tem, mais urubu ameaça/ Peguei o balaio, fui na feira/ Roubar tomate e cebola/ Ía passando uma véia, pegou a minha cenoura/ Ai minha véia, deixa a cenoura aqui/ Com a barriga vazia não consigo dormir/ E com o bucho mais cheio comecei a pensar/ Que eu me organizando posso desorganizar/ Que eu desorganizando posso me organizar/ Da lama ao caos/ Do caos à lama/ Um homem roubado nunca se engana/ Oh Josué eu nunca vi tamanha desgraça/ Quanto mais miséria, mais urubu ameaça. 


\section{ABSTRACT}

This review is about the phenomenon of hunger and its social repercussions, thought of as the greatest Brazilian expert on the subject, Josué de Castro. The study of hunger in the intellectual production of the writer is taken, in this work, as a result of a confrontation between their personal experiences and the historical reality of the time. We will cover, directly, the period that corresponds to developmentalism in Brazil, when it was prioritized investment in the industry, as the main economic activity for their development, leaving, in background, the government and the agro-rural activities. The transformations which passed Brazil, in that historical period, formed the scenario to perpetuate the hunger, here and in others developing countries of the world.

KEYWORDS: Hunger; Land Reform, Social Policy; Social Structure

\section{REFERÊNCIAS BIBLIOGRÁFICAS}

ANDRADE, M. C. de et. al. Josué de Castro e o Brasil. São Paulo: Ed. Fundação Perseu Abramo, 2003.

CAMARgO, J. F. de. Êxodo Rural no Brasil: formas, causas e consequências econômicas principais. Rio de Janeiro: Ed. Conquista, 1960.

CAMPOS, R. R. de. A dimensão populacional na obra de Josué de Castro. Tese de Doutorado. Programa de Pós-Graduação em Geografia da Universidade Estadual Paulista (UNESP), São Paulo, 2004.

CARDOSO, M. L. Ideologia do Desenvolvimento - Brasil: JK - JQ. Rio de Janeiro: Editora Paz e Terra, 1978.

CAStro, A. M. de. Fome: um tema proibido, últimos escritos de Josué de Castro. Rio de Janeiro: Civilização Brasileira, 2003.

CASTRO, J. de. O Problema da Alimentação no Brasil. São Paulo / Rio de Janeiro: Companhia Editora Nacional, 1933. 
A Alimentação Brasileira à Luz da Geografia Humana. Rio de Janeiro: Livraria do Globo, 1937.

O Livro Negro da Fome. São Paulo: Editora Brasiliense, 1960.

Ensaios de Geografia Humana. São Paulo: Editora Brasiliense, 1966.

Sete Palmos de Terra e um Caixão: ensaio sobre o Nordeste, área explosiva.

São Paulo: Brasiliense, 1967.

Documentário do Nordeste. São Paulo: Editora Brasiliense, 1968.

. Homens e Caranguejos. Rio de Janeiro: Civilização Brasileira, 2005.

. Geografia da Fome - O dilema brasileiro: pão ou aço. Rio de Janeiro:

Civilização Brasileira, 2006.

FREYRE, G. Nordeste: aspectos da influência da cana sobre a vida e a paisagem do Nordeste do Brasil. Rio de Janeiro: José Olympio Editora, 1951.

JAGUARIBE, H. ISEB: um breve depoimento e uma apreciação crítica. Rio de Janeiro: Cadernos de Opinião, n. 14, 1979.

LEBRET, L. J., VIAU, P. et. al. Propriedade e Socialização. Porto: Livraria Editora Figueirinhas, 1965.

MELO, M. M. de, NEVES, T. C. W. (Orgs). Josué de Castro: Perfis Parlamentares n. 52. Brasília: Editora Plenarium, 2007.

MYRDAL, G. Teoria Economia e Regiões Subdesenvolvidas. Rio de Janeiro: Ed. Saga, 1972.

TOLEDO, C. N. de. ISEB: Fábrica de Ideologias. São Paulo: Ed. Ática, 1977.

VIANNA, L. W. O Moderno na Política Brasileira. São Paulo: Presença Revista de Política e Cultura, Editora Caetés, $n^{\circ}$. 5, janeiro 1985.

WEFFORT, F. C. O Populismo na Política Brasileira. Rio de Janeiro: Paz e Terra, 1986. 